\title{
A quantitative kinetic study on low temperature oxidation and hydroxidation of rare earth elements
}

\author{
Hirohisa UCHIDA, Daisuke KATSUYA and Fujio SUZUKI \\ Department of Applied Physics, Tokai University \\ Kitakaname 1117, Hiratsuka, Kanagawa 259-1292, Japan \\ Tel: +81-463-58-1211(EX.4136) Fax: +81-463-58-9461 e-mail: Oaasm007@keyaki.cc.u-tokai.ac.jp \\ (Received 15, October 2001 Accepted 7, December 2001)
}

\begin{abstract}
We measured the oxidation kinetics of rare earth elements at room temperature. Until present, most work on oxidation of metals have been concerned for high temperature oxidation. We report that the surface of rare earths becomes oxidized and/or hydroxidized even at room temperature. This information is of great importance for materials conservation.
\end{abstract}

Keywords: oxides, hydroxides, surface process, low temperature, rare earth elements

\section{INTRODUCTION}

As well known, rare earths form various functional intermetallic compounds with transition metals such as hydrogen storage alloys $\left(\mathrm{LaNi}_{5}, \mathrm{Mm}\right.$ (mish metal) $\mathrm{Ni}_{5}$ ) and magnetic materials $\left(\mathrm{TbFe}_{2}\right.$, $\mathrm{Nd}_{2} \mathrm{Fe}_{14} \mathrm{~B}$ ). However, rare earths included in the compounds have high reactivity with $\mathrm{O}_{2}$ and $\mathrm{H}_{2} \mathrm{O}$ even at room temperature. ${ }^{1,2,3}$ Actually, the surface oxidation of $\mathrm{Nd}_{2} \mathrm{Fe}_{14} \mathrm{~B}$ type magnet is well known. In addition, the loss of such valuable materials is a serious problem for our future. In this study, we measured the oxidation kinetics of rare earth elements at room temperature. Until present, most work on oxidation of metals have been concerned for high temperature oxidation. We report that the surface of rare earths becomes oxidized and/or hydroxidized even at room temperature. This information is of great importance for materials conservation.

\section{EXPERIMENTAL CONDITION}

An ultra high vacuum system was used for the measurements of the reaction probability $r$ of gases of $\mathrm{O}_{2}$ and $\mathrm{H}_{2} \mathrm{O}$ with rare earth elements and the reacted gas amount $\mathrm{N}$. Details of the measurement are reported elsewhere. ${ }^{4,5}$ After degassing treatment of metal samples, the samples were evaporated onto reaction vessel until the sample film thickness attained to $100 \mathrm{~nm}$. The purity of used gases were $99.99 \%\left(\mathrm{O}_{2}\right.$ gas $)$ and $15 \mathrm{M} \Omega \mathrm{cm}\left(\mathrm{H}_{2} \mathrm{O}\right.$ gas $)$. Reaction gases were introduced to reaction vessel through receiver, capillary.

\section{RESULT}

\section{III-A. $\mathrm{Ln}-\mathrm{O}_{2}$ systems}

In this study, the reacted gas amount of $\mathrm{N}$ is expressed in molecules $\mathrm{cm}^{-2}$ or monolayers (ML), where $1 \mathrm{ML}=10^{15}$ molecules $\mathrm{cm}^{-2}$. And the reaction probability $r$ is defined as the ratio of the rate of gas adsorption of gas molecules to the impinging rate of gas molecules on the metal surface.

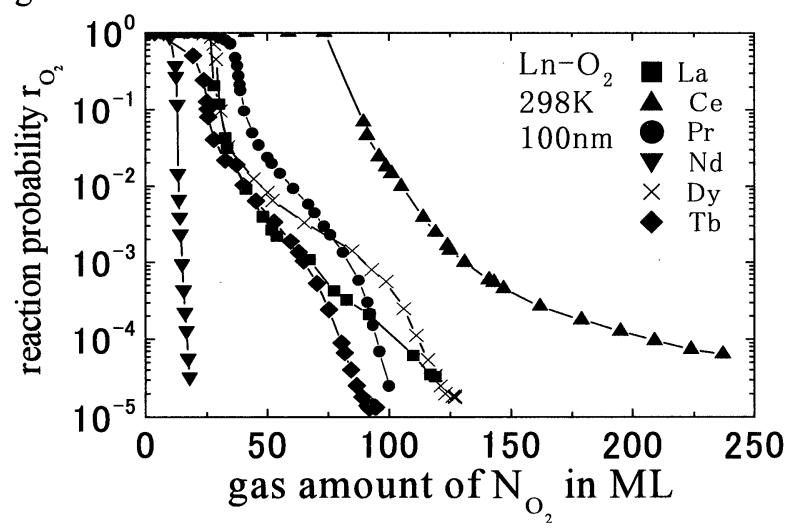

Fig. 1. $\mathrm{O}_{2}$ reactivity with each rare earth(La, Ce, $\mathrm{Nd}, \mathrm{Dy}, \mathrm{Tb})$.

Table 1. Heat of solutions in $\mathrm{kJ} / \mathrm{mol} \mathrm{O}$.

\begin{tabular}{|c|c|c|c|c|c|c|}
\hline $\mathrm{La}_{2} \mathrm{O}_{3}$ & $\mathrm{Ce}_{2} \mathrm{O}_{3}$ & $\mathrm{Pr}_{2} \mathrm{O}_{3}$ & $\mathrm{Nd}_{2} \mathrm{O}_{3}$ & $\mathrm{Sm}_{2} \mathrm{O}_{3}$ & $\mathrm{Dy}_{2} \mathrm{O}_{3}$ & $\mathrm{~Tb}_{2} \mathrm{O}_{3}$ \\
\hline-598.3 & -599.0 & -603.5 & -602.9 & -611.1 & -609.6 & -622.2 \\
\hline
\end{tabular}

Table 2 . Activation energy of oxygen in $\mathrm{kJ} / \mathrm{mol} \mathrm{O}$.

\begin{tabular}{|c|c|c|c|c|}
\hline $\mathrm{CeO}_{1.818}$ & $\begin{array}{c}\mathrm{Pr}_{7} \mathrm{O}_{12} \\
\text { (low temp }\end{array}$ & $\begin{array}{c}\mathrm{Pr}_{7} \mathrm{O}_{12} \\
\text { (high temp) }\end{array}$ & $\mathrm{Nd}_{2} \mathrm{O}_{3}$ & $\mathrm{Sm}_{2} \mathrm{O}_{3}$ \\
\hline 41.9 & 34.4 & 79.74 & 130 & 98.4 \\
\hline
\end{tabular}


In $\mathrm{Ln}(\mathrm{La}, \mathrm{Ce}, \mathrm{Pr}, \mathrm{Nd}, \mathrm{Tb}, \mathrm{Dy})-\mathrm{O}_{2}$ systems (Fig. 1 ), reaction probability $\mathrm{r}_{\mathrm{O} 2}=1$ is shown at the initial stage. These results mean that $\mathrm{Ln}-\mathrm{O}_{2}$ systems have high reactivity of $\mathrm{O}_{2}$ with rare earths films with a clean surface even at low temperature. This means that the clean surface of $\mathrm{Ln}$ ( $\mathrm{La}, \mathrm{Ce}, \mathrm{Pr}, \mathrm{Nd}, \mathrm{Tb}, \mathrm{Dy}$ ) can readily exchange electrons with the covalent $\mathrm{O}_{2}$ molecules to dissociate the molecules into $\mathrm{O}$ atoms. The length of region of the highest reactivity $\mathrm{r}_{\mathrm{O} 2}=1$ differs for each rare earth element respectively. Based on the Fromm - Mayer model, the length $L$ of the region of the highest reactivity is proportional to the ratio of heat of reaction of oxygen solution $\Delta H_{S}$ in a metal to activation energy $A_{D}$ of oxygen atom in a metal: $L=\left|\Delta H_{S}\right| / A_{D} .{ }^{6,7}$ This model argues that $\mathrm{L}$ should become longer with negatively increasing heat of solution, and shorter with increasing activation energy for diffusion. In fact, the penetration of oxygen atoms into a metal at low temperature cannot be explained simply by conventional diffusion mechanisms of oxygen at high temperatures over $500 \mathrm{~K}$. The formation of oxide layers on the metal surface by actual occurrence of oxygen atoms in the surface region is explained by complex mechanisms of the changing flow rates of electrons and ions between the metal surface and oxide layers as the layers grow. 8,9 Reported $\Delta H_{S}$ and $A_{D}$ are given in Table. 1 and $2{ }^{10}$ For each rare earth used in this study, $\Delta \mathrm{H}_{\mathrm{S}}$ values are similar, however, $A_{D}$ has quite different values. From these, the different values of $A_{D}$ seem responsible for the different length of $\mathrm{L}$.

With increasing $\mathrm{N}$, the value of $\mathrm{r}_{\mathrm{O} 2}$ decreases differently for each rare earth. This different behaviors in decreasing in $\mathrm{r}_{\mathrm{O} 2}$ are surely influenced, firstly, by the length of the initial stage $\mathrm{r}_{\mathrm{O} 2}=1$, and secondly, by decreasing metallic features of each rare earth element as surface oxidation proceeds. The $\mathrm{Ce}$ surface can exhibit a higher oxidation state, $\mathrm{Ce}^{+3}$. This may exhibit a prolonged oxidation even at lower reactivities than $\mathrm{r}_{\mathrm{O}_{2}}<10^{-3}$. The $\mathrm{Nd}$ surface exhibits a very low reactivity compared with other elements. A high $A_{D}$ value may be responsible for the low activity (Table 2).

\section{III-B. $\mathrm{Ln}-\mathrm{H}_{\mathbf{2}} \mathrm{O}$ systems}

In metal $-\mathrm{H}_{2} \mathrm{O}$ systems, we define the following relation

$$
\begin{aligned}
\mathrm{H}_{2} \mathrm{O} \rightarrow \mathrm{O}+(\beta) 2 \mathrm{H} \text { (adsorbed) } & \\
& +(1-\beta) \mathrm{H}_{2} \text { (desorbed) }
\end{aligned}
$$

where $\beta$ which is the dissociation rate of the $\mathrm{H}$ atoms from $\mathrm{H}_{2} \mathrm{O}$, is estimated from the measurement of the increasing $\mathrm{H}_{2}$ partial pressure. ${ }^{1,11}$

In $\mathrm{Ln}$ ( $\mathrm{La}, \mathrm{Ce}, \mathrm{Pr}, \mathrm{Nd}, \mathrm{Tb}, \mathrm{Dy})-\mathrm{H}_{2} \mathrm{O}$ systems, the initial reactivity of $\mathrm{H}_{2} \mathrm{O}$ is $\mathrm{r}_{\mathrm{H} 2 \mathrm{O}}=1$ (Fig.2 and Fig.3).
This means that dissociated atoms $(\mathrm{H}, \mathrm{O}$ and $\mathrm{OH})$ from $\mathrm{H}_{2} \mathrm{O}$ are reacted with the surface of rare earths. As oxide and hydroxide layers grow, $\mathrm{r}_{\mathrm{H} 2 \mathrm{O}}$ (Fig.2) and $\mathrm{r} 2 \mathrm{H} / \mathrm{H} 2 \mathrm{O}$ (Fig.3) decrease. This argument is demonstrated also by the change in the $\beta$ factor. $\beta$ is decreased as the reactivity of the $\mathrm{H}$ atoms from $\mathrm{H}_{2} \mathrm{O}$ decreases. At $\mathrm{r}_{\mathrm{H} 2 \mathrm{O}}<1, \mathrm{r}_{\mathrm{H} 2 \mathrm{O}}$ is higher than

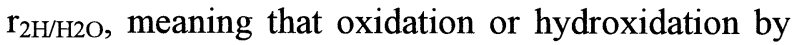
$\mathrm{O}$ or $\mathrm{OH}$ from $\mathrm{H}_{2} \mathrm{O}$ proceeds at higher rates than that of $\mathrm{H}$ uptake into metal.

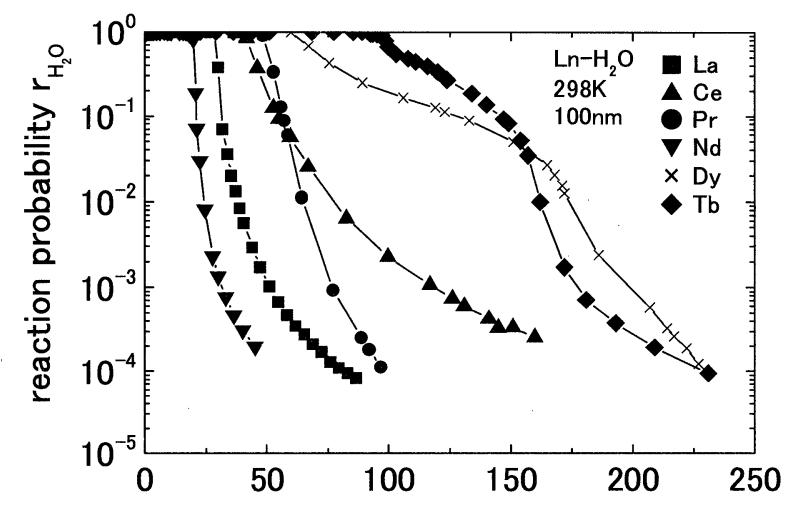

Fig.2. $\mathrm{H}_{2} \mathrm{O}$ reactivity with each rare earth s films.
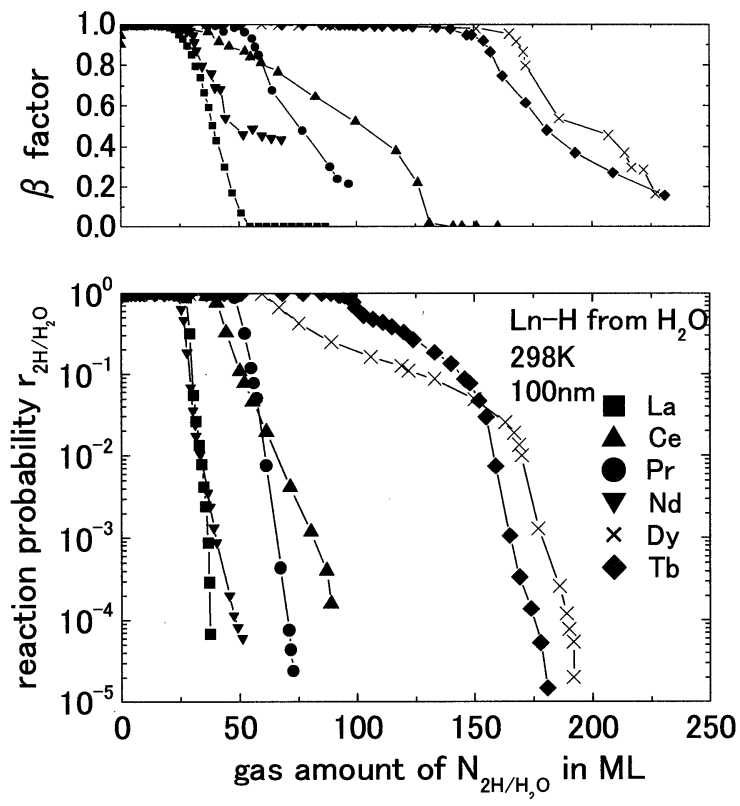

Fig.3. $\mathrm{H}$ from $\mathrm{H}_{2} \mathrm{O}$ reactivity with each rare earths films.

\section{CONCLUSION}

This study quantitatively revealed that each rare earth can be easily oxidized or hydroxidized even at 
room temperature, and demonstrated that each rare earth has different reactivity with $\mathrm{O}_{2}$ and $\mathrm{H}_{2} \mathrm{O}$ molecules. These facts should be taken into account in practical use and saving of rare earths.

\section{REFERENCES}

1 H. Uchida and E. Fromm, J. Less-Common Met. 95 (1983) 147.

2 N. Hosoda, H. Uchida, Y.Ohtani, T. Takahashi and E. Fromm, Z. Phys. Chem. N. F., 164 (1984) 103.

3 M. Hadano, N. Urushihara, T. Inoue and $\mathrm{H}$. Uchida, J. Alloys \& Comp., 293 (1999) 403.

4 S. Wagener, Br. J. Appl. Phys., 1 (1950) 225.

5 E. Fromm and H. G. Wulz, J. Less-Common Met.,101 (1984) 469.

6 E. Fromm and O. Mayer and W.Nickerson,
Surface Sci. 57 (1976) 776.

7 E. Fromm and O. Mayer, Surface Sci., 74 (1978) 259.

8 O. Kubaschewski and B. E. Hopkins, Oxidation of Metals and alloys, 2nd ed., Butterworths, London,(1962).

9 N. Cabrera and N. F. Mott, Rept. Phys. 12 (1949).

${ }^{10}$ L. Eyring, Handbook on the Physics and Chemistry of Rare Earths, Vol. 3, edited by K. Gschneider Jr.

${ }^{11}$ N. Hosoda, H. Uchida, Y. Ohtani, T. Takahashi and E. Fromm, Z. Phys. Chem. N. F., 164 (1989) 1129.

Presented at the $5^{\text {th }}$ International Conference on ECOMATERIALS Oct. 2-4, 2001, Honolulu, Hawaii 